\title{
Erratum to: A severe symptom phenotype in pepper cultivars carrying the Tsw resistance gene is caused by a mixed infection between resistance-breaking and non-resistance-breaking isolates of Tomato spotted wilt virus
}

\author{
José Aramburu • Luis Galipienso • Salvador Soler • \\ Luis Rubio • Carmelo López \\ Published online: 5 October 2015 \\ (C) Springer Science+Business Media Dordrecht 2015
}

Erratum to: Phytoparasitica (2015))

DOI 10.1007/s12600-015-0482-1

Please note an error in the original paper by authors, it is in the acknowledgments section. This research was supported by grants RTA2008-00010-C03 and RTA2013-00047C02 from the Instituto Nacional de Investigaciones Agrarias (INIA) and also by FEDER 2014-2020 funds. The corrected sentence is now shown below.

Acknowledgements We thank M. Matas for locating commercial crops of pepper carrying the Tsw gene infected with TSWV and F. Aparicio for his excellent review of the manuscript. This research was supported by grants RTA2008-00010-C03 and RTA2013-00047-C02 from the Instituto Nacional de Investigaciones Agrarias (INIA), cofunded with FEDER 2014-2020 funds.

The online version of the original article can be found at http:// dx.doi.org/10.1007/s12600-015-0482-1.

J. Aramburu

Institut de Recerca i Tecnología Agroalimentaries (IRTA), Ctra. de Cabrils Km 2, 08348 Cabrils, Barcelona, Spain

L. Galipienso • L. Rubio

Instituto Valenciano de Investigaciones Agrarias (IVIA),

46113 Moncada, Valencia, Spain

S. Soler · C. López $(\bowtie)$

Instituto de Conservación y Mejora de la Agrodiversidad

Valenciana, Universitat Politècnica de Valencia (COMAV-UPV),

Camino de Vera s/n, 46022 Valencia, Spain

e-mail: clopez@upvnet.upv.es 